\title{
Development Trend of Global Green Building Materials Industry Based on Patent Analysis
}

\author{
Ma Yanfei ${ }^{1}$, Zhang Zhenqi ${ }^{2}$ \& Zhi Liping ${ }^{3}$ \\ ${ }^{1}$ Teacher of School of Civil Engineering and Architecture, Anyang Normal University, Anyang, China \\ ${ }^{2}$ M.A student of Anyang Normal University, Anyang, China \\ ${ }^{3} \mathrm{Ph}$. D of School of Computer Science \& Information Engineering, Anyang Normal University, Anyang, China \\ Correspondence: Zhi Liping, School of Computer Science \& Information Engineering, Anyang Normal University, \\ Anyang, China. Tel: 1-350-372-8754. E-mail: zhiliping1216@163.com
}

Received: June 6, 2018; Accepted: June 27, 2018; Published: June 29, 2018

The research is financed by the Henan Philosophy and Social Science Project (No. 2015CZH004) \& the Training Scheme for Young Key Teachers in Universities of Henan (No. 2016GGJS-123) \& the Key Project of Science and Technology Research of Education Department of Henan (No. 16A520040) \& the Humanities and Social Science Project of Education Department of Henan (No. 2017-ZDJH-002) \& the Soft Science of Intellectual Property Rights of Henan (No. 20170106026).

\begin{abstract}
Using the incopat intelligence platform, the development status of the current green building materials was analyzed from the perspectives of IPC technology composition, patent licensing, patent transfer, patent applications, and patent types. It is concluded that the global green building materials industry is unbalanced in development, and it is necessary to strengthen industrial exchanges and development between countries, to jointly promote and achieve a win-win situation; Despite the high number of patents in China, the patent translation rate of Chinese universities and research institutes is relatively low, and the government should establish a communication platform between industry, universities, and research institutes to gain an in-depth understanding of market demand, which would help to patent transfer.
\end{abstract}

Keywords: green building materials; patent analysis; Incopat

\section{Introduction}

For the past few years, in order to seek new economic growth points and improve people's livelihood, countries around the world have begun to invest more in infrastructure construction, and which requires a lot of construction materials, so green building materials technology is becoming more and more important(Hua Jian,2003:46).

The difference between green building materials and traditional building materials is that green building materials are designed to use as few natural resources as possible, promote the use of renewable resources and recycled or recyclable materials, improve production technology, reduce energy consumption and reduce the impact on the environment(Li Xiangzhou,2000:51). Produce non-toxic, harmless or low-toxic products while meeting fire protection, insulation, noise reduction, dimming and anti-static functions of houses(Zhu Yuhua,2001:40). We must follow the principle of sustainable development so as to reduce the burden on the earth's ecosystem, realize the efficient use and recycling of resources, and provide guarantees for human survival and development. Promoting the development of green industries can stimulate green development and promote industrial transformation and upgrading(Shi Huisheng,2007:9).

2 Data Sources and Patent Search

We choose Incopat Technology Innovation Intelligence Platform (www.incopat.com) as source of the data, as incopat has a wide collection of patents, authoritative sources of data, and fast update speeds. This provides the latest and most comprehensive basic data for the analysis of patented technologies (Bai Shangping,2008:102; Zhang Mingqing,2008:151). 
This research was conducted on the incoPat innovation intelligence platform to retrieve and statistically analyze the patents of green building materials from 1999 to 2016 in Henan Province(Zhi Liping,2014:79). It should be noted that since the patents for inventions were applied for about three years from the time of application, the patents were entered into the database with some delay(Zhi Liping,2014:57). Only the data before 2016 are used. This article uses the statistical data from 1999-2016 (some of them within the last 40 years) as a sample(Zhi Liping,2012:113).

In order to obtain more accurate search results, through the study of relevant patent documents, this article has determined the construction materials, building materials, structure, decoration, green, ecological, environmental protection, health, noise reduction, dimming, heat insulation, thermal insulation, flame retardant, fire prevention, The most relevant keywords such as antistatic, harmless, low energy, clean and recyclable.

\section{Patent Analysis}

\subsection{Global Green Building Materials Patent Analysis}

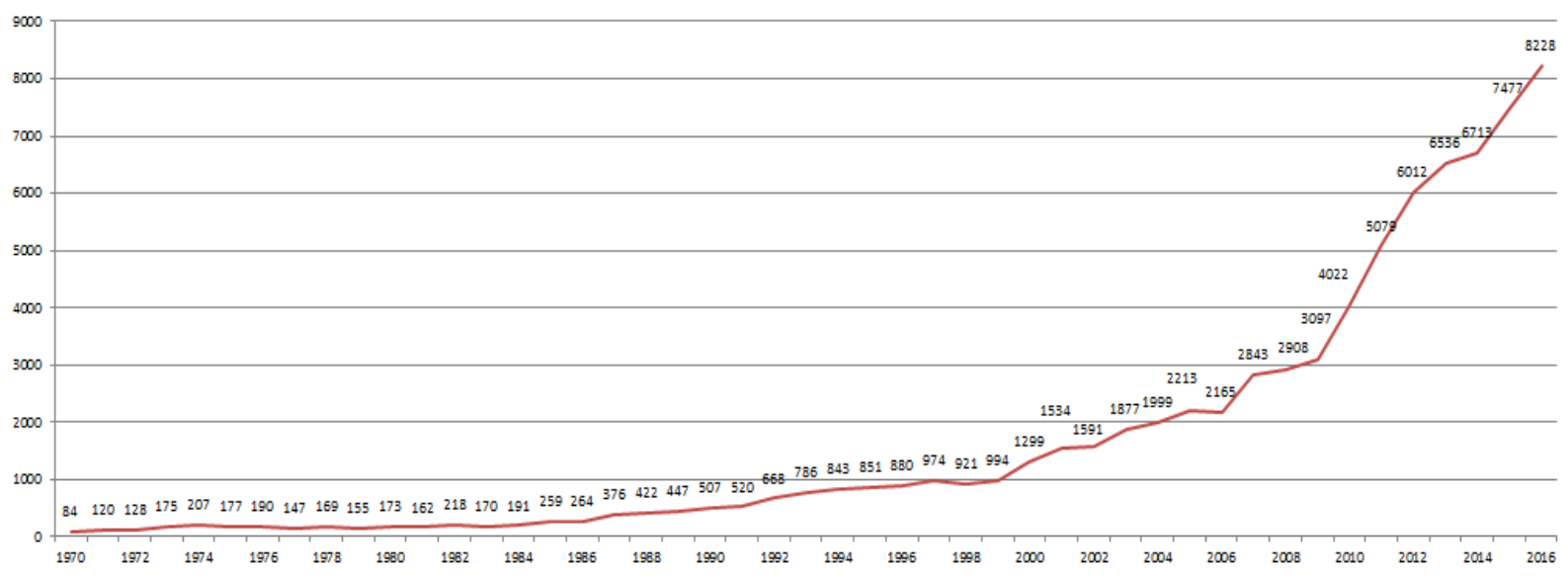

Figure 1. Annual Distribution of Global Patent Applications (1970-2016)

Global green building materials-related patents were collected from incoPat's patent database, and global green building materials industry patent application trends from 1970 to 2016 were obtained. As shown in Figure 1, the patent application for the global green building materials industry has appeared since the 1970s. According to the number of patent applications filed in the world, the global green building materials industry patent applications can be roughly divided into three stages: the 1970s to the 1980s. The medium-term is the initial stage of development. The green building materials industry has just emerged, and the number of patent applications is relatively small. From the mid 1980 s to 2005 , it was a stable development stage. The green building materials industry has developed to a certain scale, but its progress has been slow; it has been a rapid development since 2005. At the stage, the annual application volume of the green building materials industry has grown rapidly.

Among them, the ranking of green building materials patents by countries and organizations around the world is shown in Figure 2. China (excluding Hong Kong, Macao and Taiwan data) ranks first in the world in patent applications, up to 44,380, with South Korea and Japan ranking second. Three were 5358 and 3842 respectively, and South Korea was 12.07\% of China. Canada and Australia are the 11th and 12th in the world, and the number of patent applications is only $0.73 \%$ of that in China. Overall, the development of the green industry in the world is not balanced, not only between the developed countries and the developing countries, but also among the developing countries. The development of the green building materials industry in China is far ahead of the rest. Other countries and organizations in the world. 


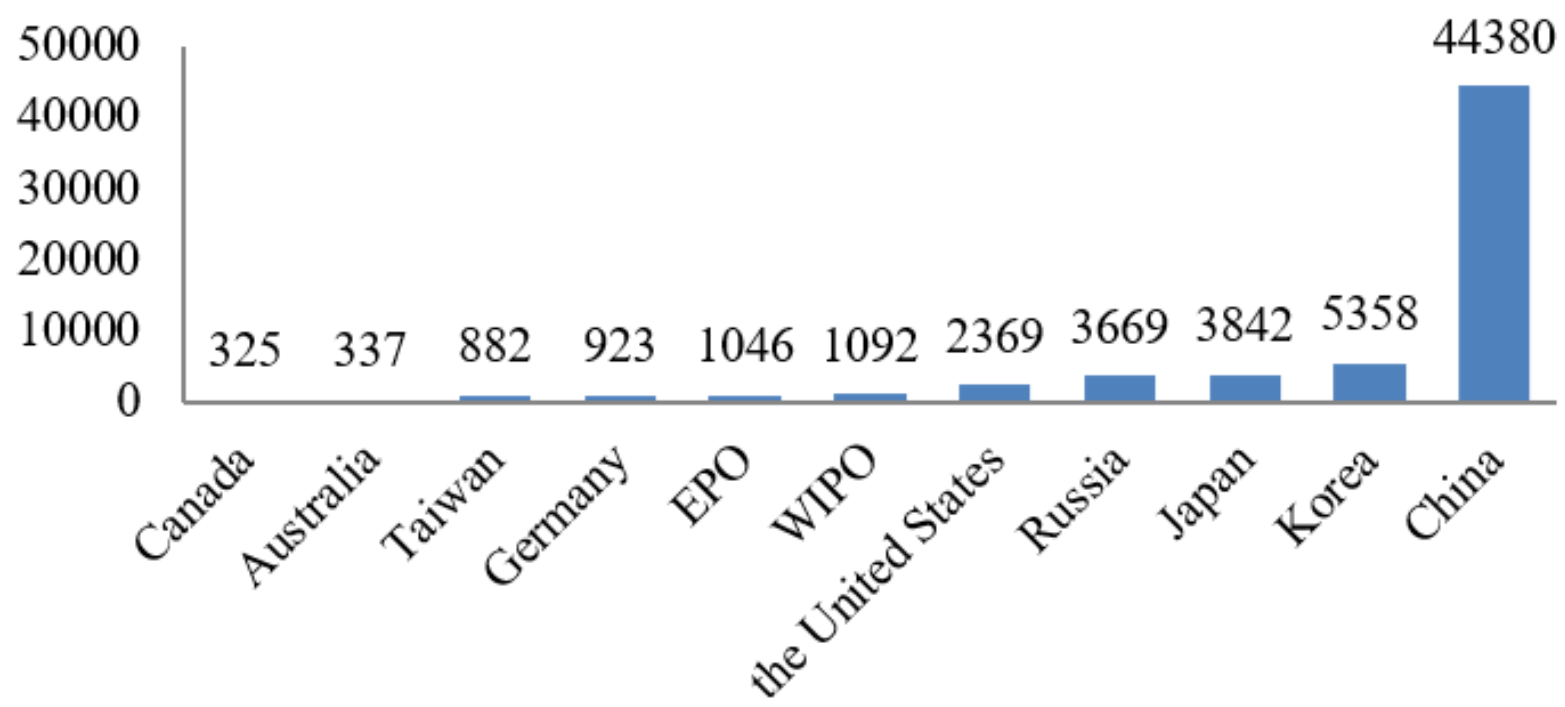

Figure 2. Patent Applications by Countries and Organizations Worldwide

As the country with the largest population in the world, China has a population of 1.379 billion (as of 2016), the third largest country in the world, and a large demand for housing and related infrastructure. It requires tens of thousands of construction materials. After the reform and opening up, the economy grew rapidly, national income and living standards gradually increased, consumption concepts and structures changed, disposable incomes continued to increase, and the green economy became the mainstream. Many conditions became the driving force for the development of the green building materials industry.

The top ten global green building materials applications in the year are mostly developed countries or organizations related to developed countries, including Germany, the United States, and Japan, which earlier proposed environmental labels. The United States and Germany have high levels of economic development and high standards of living. There is a certain degree of emphasis on environmental protection and conservation; Korea and Japan, due to lack of resources, attach great importance to energy conservation and environmental protection as well as the rational use of resources, and have strong enthusiasm.

\subsection{Analysis of Global Green Building Material Technology Composition}

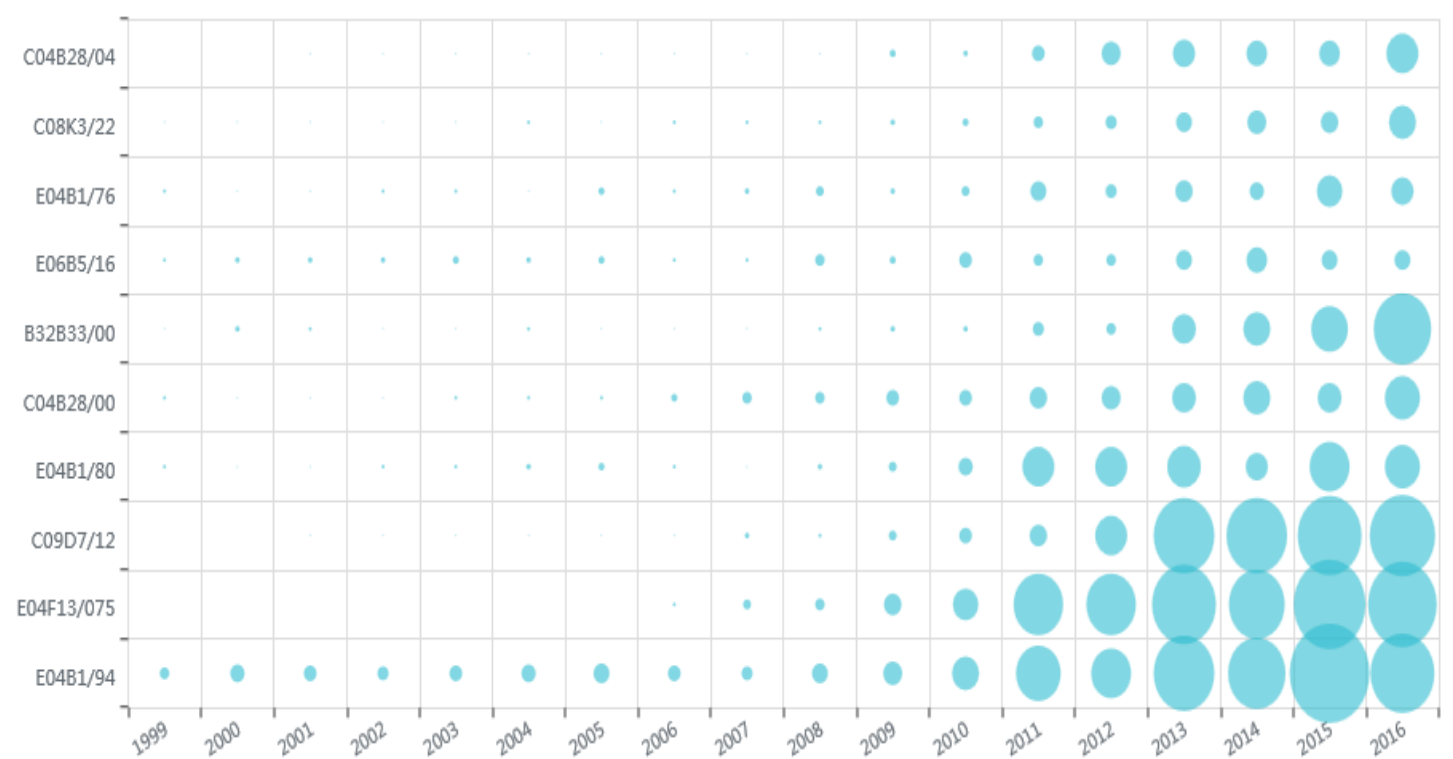

Figure 3. Trends in Patent Technology Composition of the Global Green Building Materials IndustryTable 1

Table 1 Technical Composition Analysis Table 
Table 1.

\begin{tabular}{ll}
\hline \multicolumn{1}{c}{ IPC } & \multicolumn{1}{c}{ meaning } \\
\hline E04B1/94 & Fire Protection \\
E04F13/075 & For isolation or surface protection, for example, against noise or collisions \\
C09D7/12 & Other additives \\
E04B1/80 & Plate type \\
C04B28/00 & $\begin{array}{l}\text { Compositions containing mortar, concrete or artificial stone, such as polycarboxylate cements, } \\
\text { containing inorganic binders or products containing the reaction products of inorganic and }\end{array}$ \\
B32B33/00 & $\begin{array}{l}\text { organic binders [4] } \\
\end{array}$ \\
& Laminated products characterized by special properties or special surface properties such as \\
& a separate large group, designed for special purpose Layered product) \\
E06B5/16 & Fire doors or similar closing devices; and their suitable fixing members \\
E04B1/76 & Specially used for insulation (general insulation into F16L59/00) \\
C08K3/22 & Metallic \\
C04B28/04 & Portland cement \\
\hline
\end{tabular}

The trend of global patents for green building materials is shown in Figure 3. Larger bubbles indicate more quantities. E04B1/94 (Fire Prevention (Fire Prevention Into A62C; Immersion of Wood or Similar Material Into B27K; Fire Door Into E06B5/16)) Steadily Slow Growth Between 1999 and 2009, with the Development of Category Numbers in the Later Phases The ratio is greatly improved. The technical composition is represented by the IPC classification number. The top 10 IPC classification numbers (by group) are shown in Table 2, most of them (e.g. E04B1/94, E04F13/075, E06B5/16, E04B1/76) relates to functionalized materials, followed by mortar, cement, etc., and finally interior decoration materials.

\subsection{Patent Analysis of Green Building Materials in China}

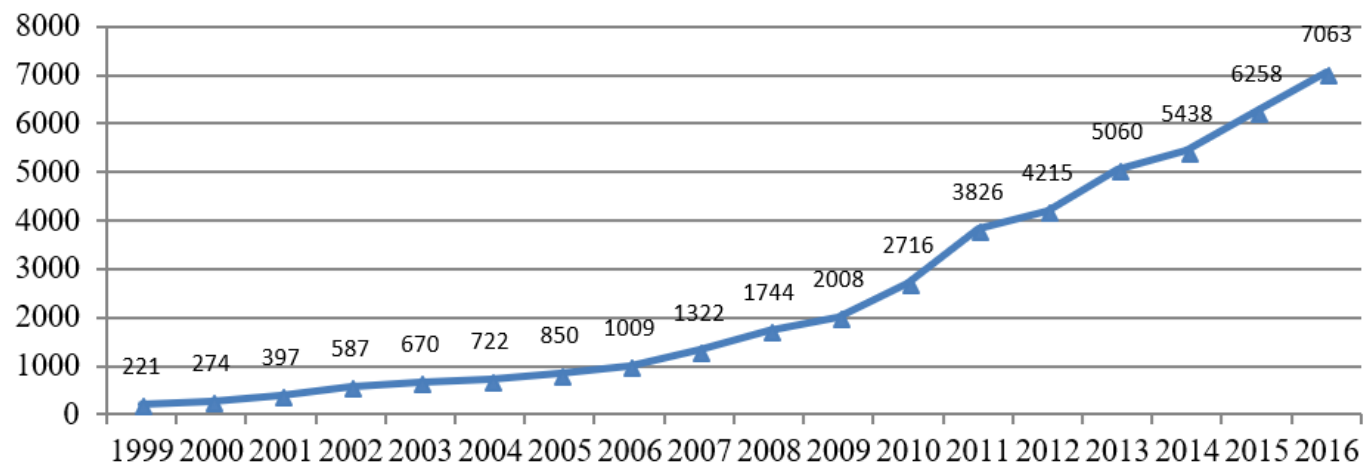

Figure 4. Patent Applications of Green Building Materials Industry in China

The number of patents related to green building materials in China was calculated from the incoPat patent database, and the number of patent applications for China Green Building Materials in 1999 was obtained. As shown in Figure 4, the growth trend of China's green building materials industry is consistent with the global industry growth trend. The annual growth rate of China's green building materials applications averaged $23.25 \%$, the highest increase was $47.86 \%$ in 2014, and the lowest increase was $7.49 \%$ in 2014 , showing a steady growth overall. The reason why the current good development status can be inextricably linked with national policies. In 1996, we established a sound environmental management system and issued corresponding evaluation standards. In the "New Action Plan for Green Buildings" announced in 2013, it is required to vigorously develop green building materials, establish a product certification system, and compile related product catalogues. In the same year, a coordination group for promotion and application of green building materials was established to jointly promote the use of green building materials in multiple sectors; 2014 The "Administrative Measures for the Evaluation of Green Building Materials Markings" was promulgated, and the meaning of "green building materials" was clearly defined and explained from various aspects. In 2015, the "Technical Guidelines for Evaluation of Green Building Materials (Test Operation)" was formulated, and 7 categories were formulated. Technical requirements for the evaluation of building materials products. The state has strengthened its attention to the green building materials 
industry, improved the evaluation and management system of related products, used the influence of the national level to promote and apply green building materials, and promoted the standardized development of the green building materials industry.

\subsection{Analysis of Chinese Patent Types}

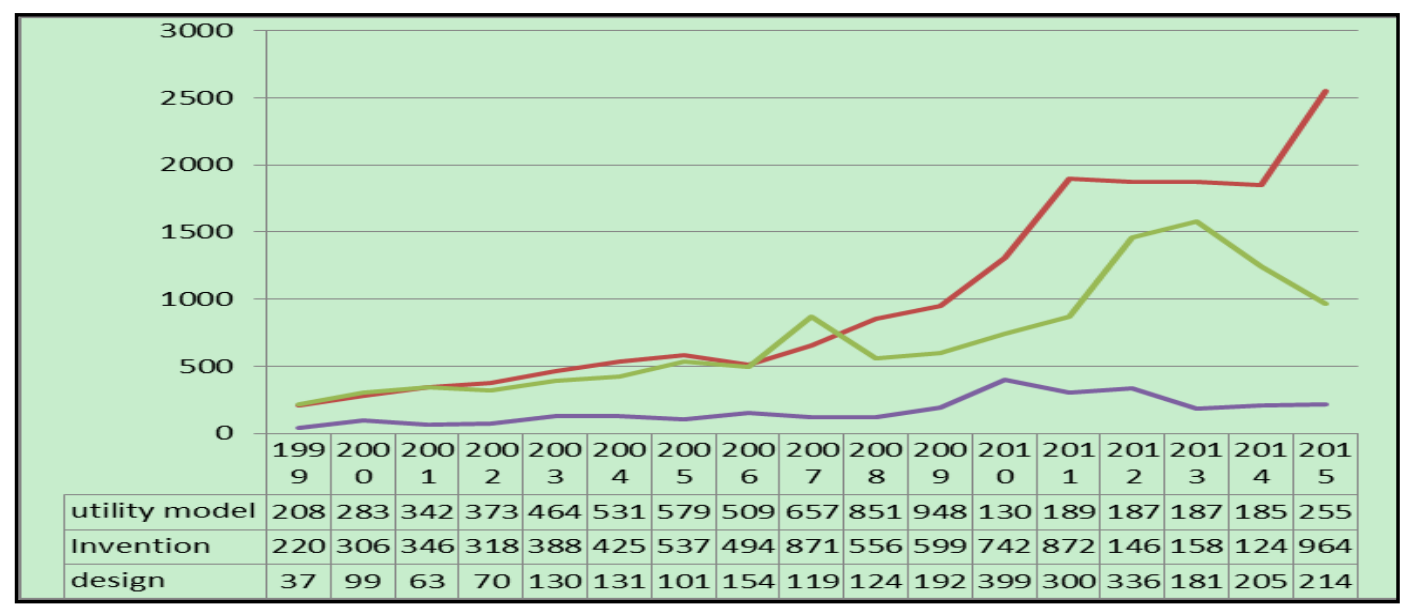

Figure 5. Analysis of Patent Types in China

China's patents mainly include inventions, utility models and designs. The status of China's patents for green building materials is shown in Figure 5. Starting in 1999, the proportion of utility models and invention authorizations was comparable, and the appearance design ranked third. In 2007, the invention authorization exceeded the utility model, reaching a maximum proportion of $52.9 \%$. The proportion of utility models began to rise in 2008, and the proportion of invention authorizations decreased by $2 \%$ each year. After 2013, utility models accounted for The proportion exceeds $50 \%$ and starts to increase at an annual rate of $9 \%$. The appearance design grew slightly in 2010-2013, reaching a peak of $16.2 \%$ in 2010, and then remained stable at a level of $9 \%$.

It can be seen from the figure 5 that China's patents for green building materials are mainly based on utility model patents, followed by inventions, and finally by appearance design. Compared to utility model patents and invention patents, the level of technological breakthrough is relatively low, and specific technical solutions are needed. However, they have high practical value, low application threshold, and low level of professional knowledge required. They are suitable for most people to try; the technologies needed for invention patents The high level of breakthrough is not limited to specific things and requires the mastery of professional knowledge and skills.

\subsection{Analysis of Technical Composition of Green Building Material Industry Patent in China}

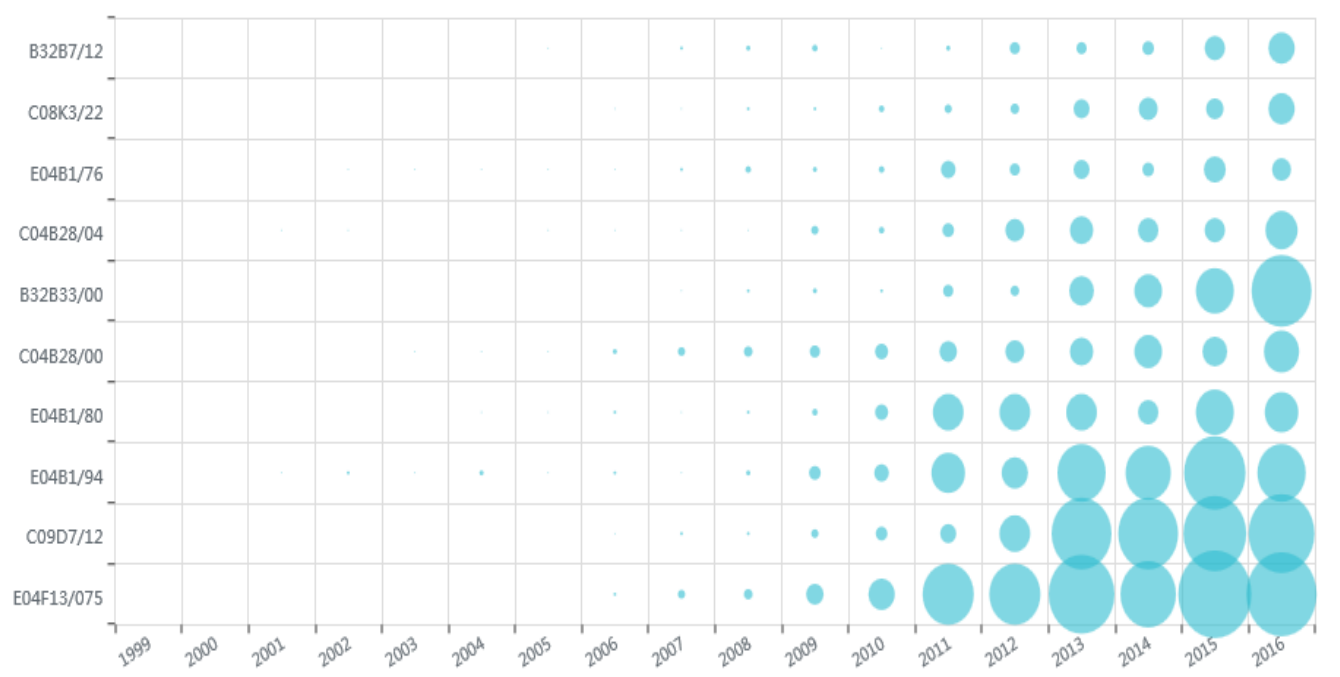

Figure 6. Technology Changes Trend 
The top 10 IPC classification numbers for green building materials patents in China (by group) are shown in Table 3. Compared with the global green building materials industry, the key areas for development are roughly the same, and all are focused on E04B1/94, E04F13/075, and E06B5 /16, E04B1/76 insulation, fire and other functional building materials.

According to the IPC classification number, the bubble of China's green building material technology composition trend is shown in Figure 6. E04F13/075 began a sudden growth in 2009, and then the growth rate tends to be flat. In 2012, C09D7/12 began to show growth momentum. More than 70\%, then the average increase was about 30\%; E04B 1/80 began to develop in 2012, after a slight fluctuation; other areas of slow development, in its infancy. On the whole, there is a big gap between the development speeds of the fields and the development areas are too single.

\subsection{Analysis of Patent Application in China}

Table 2. Types of Patent Applicants in China

\begin{tabular}{ll}
\hline Applicant type & Number of patents \\
\hline enterprises & 23736 \\
individuals & 15700 \\
colleges and universities & 4776 \\
scientific research institutions & 1009 \\
organizations & 102 \\
others & 44 \\
\hline
\end{tabular}

As shown in Table 2, the applicants for patents for green building materials in China are enterprises, the number of patents is 23,736 , accounting for $52.3 \%$, followed by individuals, accounting for $34.6 \%$; the third are colleges and universities, accounting for $10.5 \%$; and the fourth is scientific research institutions, accounting for only $2.2 \%$. It can be seen that China's patent applicants for the green building materials industry are scattered. The number of applications for each applicant is not enough. The main reason is that the scale of the company is immature. Enterprises account for more than half of the share because companies need to continue to innovate to create their own advantages under the trend of economic interests. Applying for patents can protect their own advantages at the legal level and not be infringed, and can achieve the goal of crowding out rivals to occupy market share; on the other hand, Government policy support can be obtained. Universities and research institutes accounted for only 12.7\%. Due to limited state funding, there are universities with higher levels of state subsidies, but fewer such universities can not support a large number of scientific research projects, resulting in a limited number of projects; more commercial enterprises The relationship between products and patents is closer than the relationship between research and patents, leading to the actual development of products more likely to be able to apply for patent Colleges and universities are more inclined to research and discover. The "heavy essay" has serious thoughts. As a result, the number of patent applications in universities and research institutes is small.

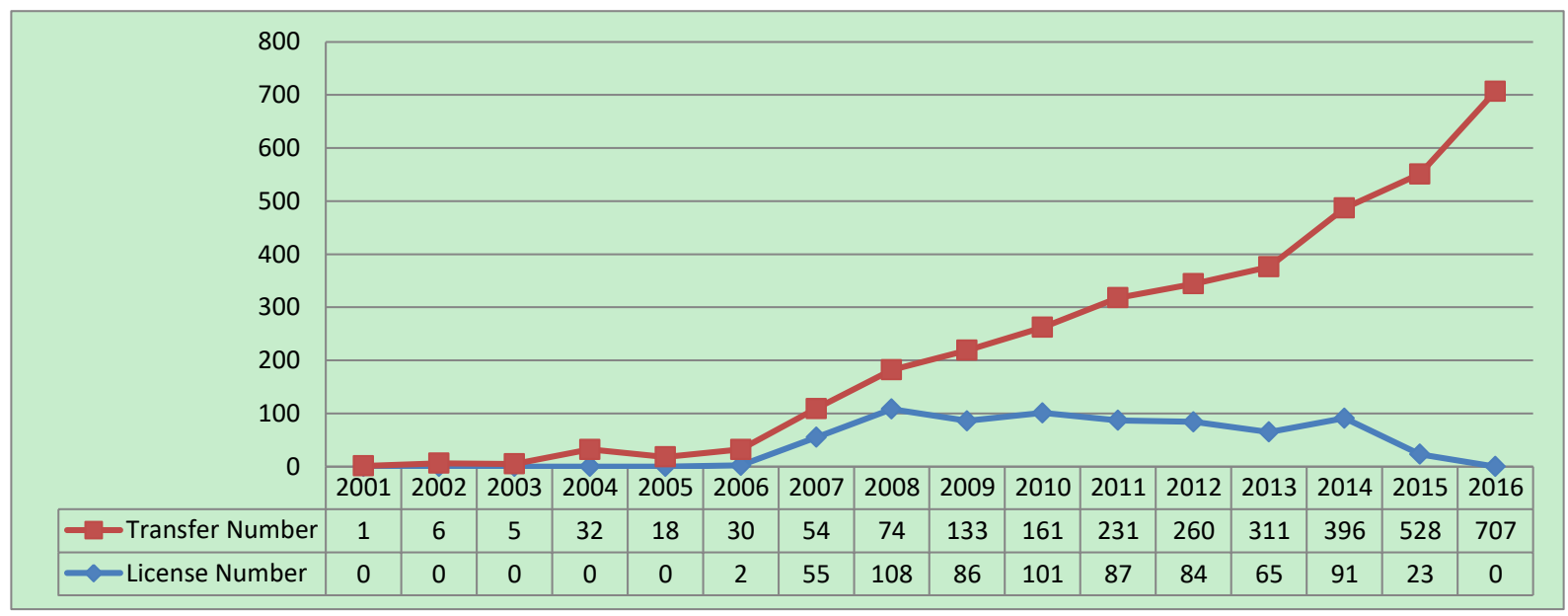

Figure 7. Trend of patent transfer in China 
As shown in Fig. 7, compared with the number of transfers, the development of green building materials patent licenses is severe. Before 2006, the number of patents for green building materials in China was 0 , peaking at 108 in 2008, and then began to fluctuate around 100. The number of patent transfers was also 10 in 2001-2006, and it began to increase substantially after 2007, reaching a peak of 707 in 2016. Compared with the number of patent applications, the number of patent assignments and licenses is negligible. Patent assignments and patent licenses can acquire their own required patents by way of transfer or license, which is more convenient and quicker. Patent licenses have a variety of licensing methods and are more mature, and the promotion of patent licenses should be increased.

\section{Existing Problems and Countermeasures}

From the perspectives of IPC technology composition, patent transfer and licensing trends, patent applications, and patent types, we analyze the current development status of green building materials and come up with the following issues and countermeasures.

\subsection{Problems}

\section{1) Unbalanced Development of Global Green Building Materials Industry}

Developed countries such as Europe, the United States and Japan started earlier, and they have been in the leading position in the world for some time before. However, with the continuous development of the green building materials industry in China, relevant supporting policies have been continuously introduced, and the Chinese green building materials industry has begun to make breakthroughs, thus surpassing other countries. The country ranks first in the world. Although China occupies a dominant position in the number of patent applications, the evaluation and management system of related products is not perfect, and the production technology is backward, and relying on domestic support alone will take a long time.

\section{2) Low Patent Technology Conversion in Universities}

Institutions of higher learning and scientific research institutions have a large number of knowledgeable people who have received higher education. The state allocates funds for scientific research project activities each year, convenient knowledge and information networks, and good research conditions, but the number of patents that are truly commercialized each year Very little. The activities of scientific research projects, mainly universities and research institutes, have different purposes. Institutions of higher learning and scientific research units do not use economic efficiency as a research evaluation index. Instead, they use theoretical knowledge as their main approach. They usually end up applying for patents, and are not capable of commercialization alone. Therefore, they do not consider the market demand in advance, resulting in the inability to proceed. Accepted by the market, thus losing the economic value of the patent itself. On the other hand, in institutions of higher learning and research institutes, ownership of patents is classified as a unit and there is no perfect reward mechanism, which will dampen the enthusiasm of R\&D personnel.

The main research projects of universities and research institutes are mainly research and discovery. They cannot link the findings and achievements directly to related products. Since there has been no good solution to the issue of piracy in China, issues left over by history have caused most people to The awareness of patent rights protection is not strong, resulting in insufficient attention to their own research results, ignoring the importance of patents; on the other hand, due to the high cost of funds for scientific research activities, the national funds are insufficient to support relevant practical testing, resulting in only theoretical cannot be actually used.

3) The value of Chinese patents is generally low

Although the number of related patents in the green building materials industry in China ranks among the top in the world, the overall patent value is generally low. Only very few patents are of high value, and fluctuations in quality fluctuate greatly. It is easy to spend a lot of time and money, which is not conducive to green building materials. The stable development of the industry.

\subsection{Countermeasures}

1) The cooperation between China, Europe, the United States, Japan, and other countries should be strengthened to learn from the excellent management system of the green building materials industry; to strengthen the construction of transportation infrastructure and to shorten the distance between commodity markets; to introduce advanced products, to integrate market resources through market competition, To stimulate the development of the domestic green building materials industry; to encourage the establishment of joint ventures through the government's lead and policy support, and to absorb outstanding management experience; to encourage 
universities and research institutes to conduct international academic cooperation, jointly research and solve problems, and promote multi-level exchanges.

2) The government shall guide enterprises, universities, and research institutes to cooperate between industry, universities and research institutes to establish a fast and effective communication platform so that the R\&D personnel of institutions of higher learning and research institutes can understand the market demand, conduct research on key areas, and develop new technologies. Technology can be transformed in time, scaled into production, and produce economic benefits. Institutions of higher learning and research institutes should establish corresponding assessment systems to link research and development with salary and job title selection, which greatly stimulates the enthusiasm of R\&D personnel. Colleges and universities and scientific research institutions should strengthen their awareness of patent rights protection and pay attention to the economic value of patents.

3) In view of the uneven quality of patents, China should establish an effective communication platform, be able to understand related patent information in a timely manner, avoid the waste of resources caused by secondary $\mathrm{R} \& \mathrm{D}$, and integrate resources, cooperate with each other, and face common scientific research issues. Solve the problem.

\section{References}

Bai, S. P. (2008). Review of Development and Trend of Green Building Materials in China. Library and Information Service, 18(35), 102-103.

Hua, J. (2003). Development of Foreign Green Building Materials. World of Tiles and Tiles, 2003(12), 46-46.

Li, X. Z. (2000). Analysis of the Development of Green Building Materials in China. China Building Materials, 2000(4), 50-52.

Shi, H. S., \& Yao, Y. M. (2007). Green building materials and its development trend (1). Building Materials Technology and Application, 2007(10), 9-11.

Zhang, M. Q. (2008). Analysis on the Development Status and Countermeasures of Green Building Materials in China. Shanxi Architecture, 34(15), 151-152.

Zhi, L. P. (2014). Technological Development Situations of Ontology in China Based on Patentometrics. Journal of Intelligence, 33(06), 79-83.

Zhi, L. P., \& Wang, H. S. (2012). A Patent Collaborative Management Model Between High-Tech Enterprises. Science of Science and Management of S.\& T., 33(09), 113-121.

Zhi, L. P., \& Zhang, S. L. (2014). Research on Semantic Retrieval Based on Patent Ontology. Research on Library Science, 2014(07), 57-61.

Zhu, Y. H. (2001). Research on the Development of China's Green Building Materials Market. Wuhan University of Technology, 2001(4), 40-43.

\section{Copyrights}

Copyright for this article is retained by the author(s), with first publication rights granted to the journal.

This is an open-access article distributed under the terms and conditions of the Creative Commons Attribution license (http://creativecommons.org/licenses/by/4.0/). 